\title{
Kalkidan ('Promise') preventing marital transmission of HIV in urban Ethiopia
}

Annabel Erulkar

Population Council

Hanan Nourhussein

Population Council

Follow this and additional works at: https://knowledgecommons.popcouncil.org/departments_sbsr-pgy

Part of the Demography, Population, and Ecology Commons, Family, Life Course, and Society Commons, and the International Public Health Commons How does access to this work benefit you? Let us know!

\section{Recommended Citation}

Erulkar, Annabel and Hanan Nourhussein. 2014. "Kalkidan ('Promise') preventing marital transmission of HIV in urban Ethiopia." Addis Ababa: Population Council. 


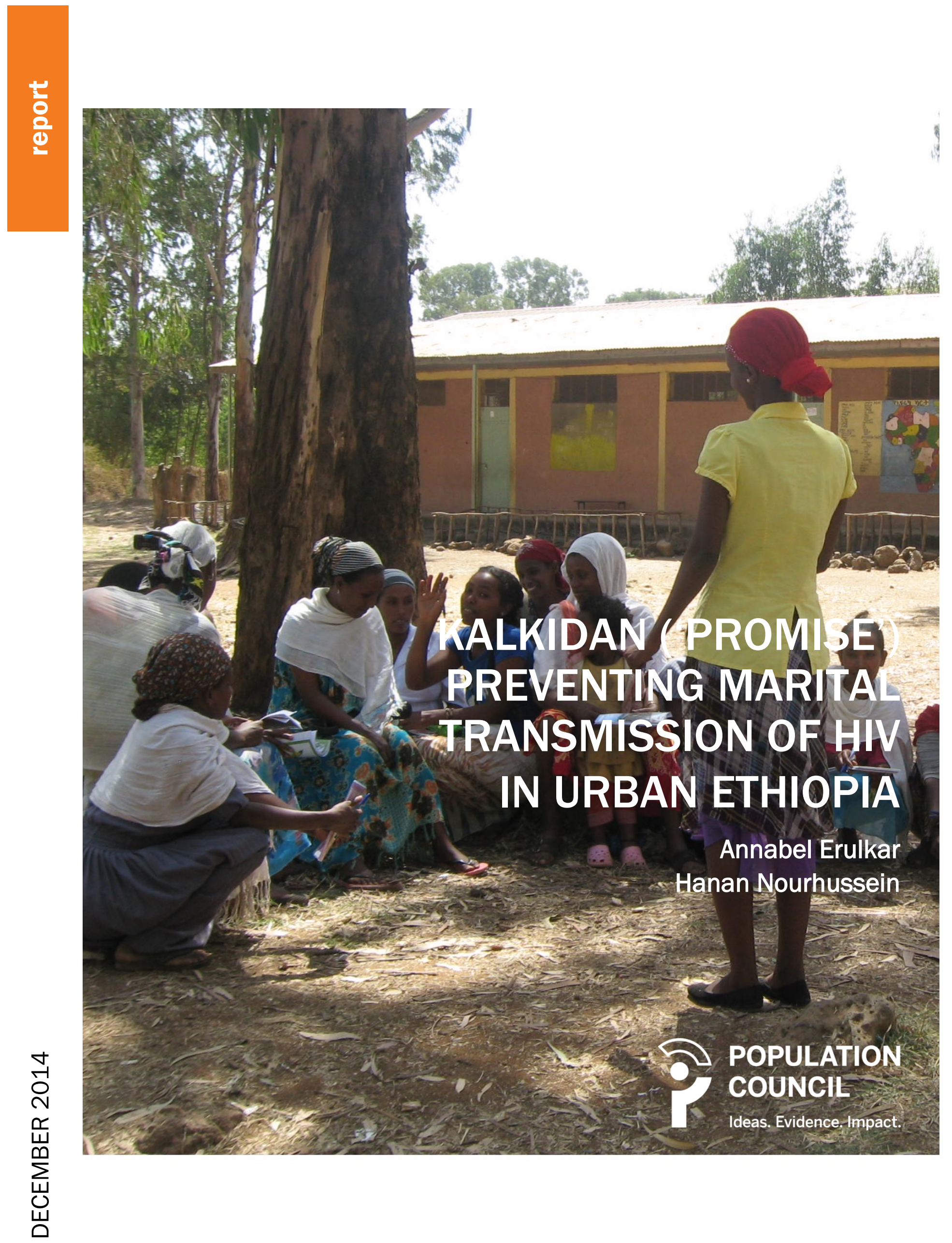




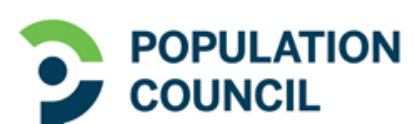 \\ Ideas. Evidence. Impact.}

The Population Council confronts critical health and development issues-from stopping the spread of HIV to improving reproductive health and ensuring that young people lead full and productive lives. Through biomedical, social science, and public health research in 50 countries, we work with our partners to deliver solutions that lead to more effective policies, programs, and technologies that improve lives around the world. Established in 1952 and headquartered in New York, the Council is a nongovernmental, nonprofit organization governed by an international board of trustees.

Population Council

P.O. 25562, Code 1000

Addis Ababa, ETHIOPIA

Tel: (251) (0) 116-631-712/4/6

popcouncil.org

Annabel S. Erulkar, MSc, PhD, is Country Director of the Population Council's Country Office in Ethiopia

Hanan Nourhussein is Program Officer in the Population Council's Ethiopia Country Office.

Suggested citation: Erulkar A, Nourhussein H. 2014. “Kalkidan ('Promise') Preventing Marital Transmission of HIV in Urban Ethiopia," Addis Ababa: Population Council. 


\section{Table of Contents}

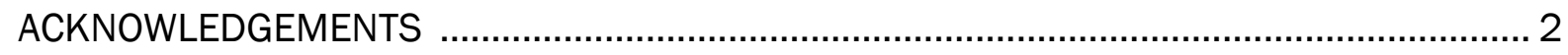

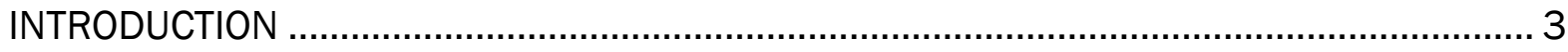

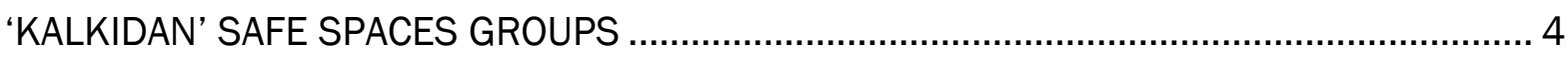

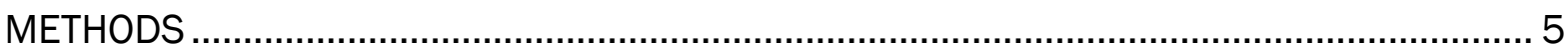

Baseline survey.....5

Service statistic data.....5

Qualitative studies of perception of the program.....6

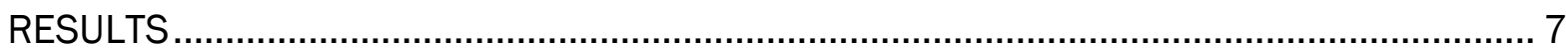

Baseline survey.....7

Service statistics.....11

Qualitative study of the program.....12

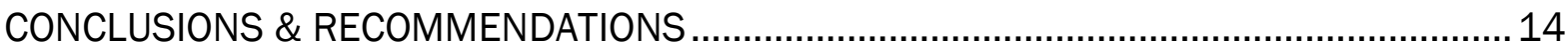




\section{Acknowledgments}

The authors gratefully acknowledge the support of the Tigray Bureau of Health, Tigray Bureau of Youth \& Sport Affairs, Bahir Dar HIV Prevention and Control Office (HAPCO), and the Addis Ababa HAPCO. We are very grateful for the involvement and support of local officials in Addis Ababa, Bahir Dar and Mekelle at all stages of this research. Population Council staff oversaw implementation of the project including Habtamu Demele, Assefa Shiferaw, Getachew Kassa, and Ayenachew Kerie, among others. Frehiwott Getachew managed analysis of the service statistics and Amanda Spiegelberg assisted with proofreading and editing. We would also like to thank the respondents in the research and participants in the program. We are grateful to Viiv Healthcare/Positive Action for Children Fund (PACF) for support to this program. 


\section{Introduction}

HIV prevalence in urban Ethiopia in 2014 was estimated as 3.5 percent (2.6 percent among males and 4.3 percent among females). In rural areas, it is 0.5 percent. ${ }^{1}$ Peak prevalence is among ever married women in their 30's, suggesting a substantial number of women may be infected by husbands. ${ }^{2}$

However, few programs take into account the HIV risk experienced within the context of marriage, which has been related to increased sexual frequency and diminished condom use,. ${ }^{3}$ Likewise, few programs effectively address women's limited power and decision-making in locations where traditional gender norms prevail, as well as infidelity between partners. Ethiopia is a traditional country, with most women experiencing sexual initiation within marriage. Indeed, among Ethiopian women aged 20 to 49, median age at first marriage and first sex are identical, 16.5 years. ${ }^{4}$ Recent studies by the Population Council among 6,000 women in seven regions found that 10 percent of urban women feared their spouse would give them HIV, and 17 percent suspected infidelity. ${ }^{5}$ In a study of 1,500 people living with HIV/AIDS (PLWHA), 67 percent of females suspected that their husband was the source of infection. ${ }^{6}$ Furthermore, among women in the same study, 61 percent agreed with the statement " $A$ woman should not be able to refuse her husband sex." Only 45 percent of respondents had talked to their husbands about HIV/AIDS.

Most mainstream HIV prevention programs focus on increasing knowledge related to HIV transmission and risky sexual behaviors. While important, these initiatives often do not take into account gender issues or power dynamics, nor do they address the risk that marital partners face within their relationships. Implicitly, such programs assume that marriage is a safe haven for women and that their HIV risk is minimal. In response, the Population Council launched the 'Kalkidan' project to enhance couple communication, promote HIV prevention within marriage, reduce stigma and violence, and increase demand for HIV information and services, including prevention of mother-to-child transmission (PMTCT)-which will collectively contribute to HIV-negative women remaining negative.

\footnotetext{
${ }^{1}$ Ethiopia Public Health Inst. \& Federal Min. of Health (FMOH). 2014. 'HIV related estimates and projects for Ethiopia-2014,' Addis Ababa: $\mathrm{FMOH}$, July.

2 Central Statistical Agency (CSA) and ORC Macro. 2006. Ethiopia Demographic and Health Survey 2005. Addis Ababa, Ethiopia and Calverton MD, USA: Central Statistical Agency and ORC Macro.

${ }^{3}$ Clark S, 2004. “Early marriage and HIV risks in sub-Saharan Africa” Studies in Family Planning, 35(3) 149-160.

${ }^{4}$ CSA and ORC Macro. Op. cit.

${ }^{5}$ Erulkar A, Ferede A, Ambelu W, et. al. 2010. "Ethiopia Gender Survey: A Study in Seven Regions," Addis Ababa: Population Council \& UNFPA, October.

${ }^{6}$ Girma W, Erulkar A, Dawub A. 2010 “Preventive Care Package Program for People Living with HIV/Aids in Ethiopia: Results From A Baseline Survey," Addis Ababa: PSI/Population Council report, February.
} 


\section{‘Kalkidan' Safe Spaces Groups}

'Kalkidan' is Amharic for 'promise,' and was a community-based initiative for husbands and wives in low income areas of urban Ethiopia. The project addressed the HIV risk faced by many women within the context of their regular, marital partnerships. The project was implemented in low income/slum areas of three Ethiopian cities: Addis Ababa, Bahir Dar and Mekelle. Kalkidan is a partnership with regional HIV/AIDS Prevention and Control Offices (HAPCO), regional bureaus of health, and local kebele administrations.

Through 'Kalkidan,' adults who are respected local leaders were recruited from the project communities to serve as mentors in the community. These mentors were trained on a tailored curriculum addressing power and gender issues and including topics such as caring and supportive relationships, communication, alcohol and violence, HIV transmission and prevention, couples' counseling and testing, PMTCT, family planning (FP), condom use, and maternal and child health $(\mathrm{MCH})$.

Following training, mentors go house-to-house in their locations to identify eligible participants, married men and women aged 15 to 49. Eligible participants are invited to single-sex groups led by a same-sex mentor. These groups meet on a weekly basis, generally on weekends, in local kebele community halls or other available facilities. These parallel groups of husbands and wives are periodically brought together for collective discussion and problem-solving. Groups meet for four to six months to complete the curriculum, after which they take part in a graduation ceremony. The groups aim to enhance couple communication, promote HIV prevention, reduce stigma and violence, and increase demand for HIV information and services.

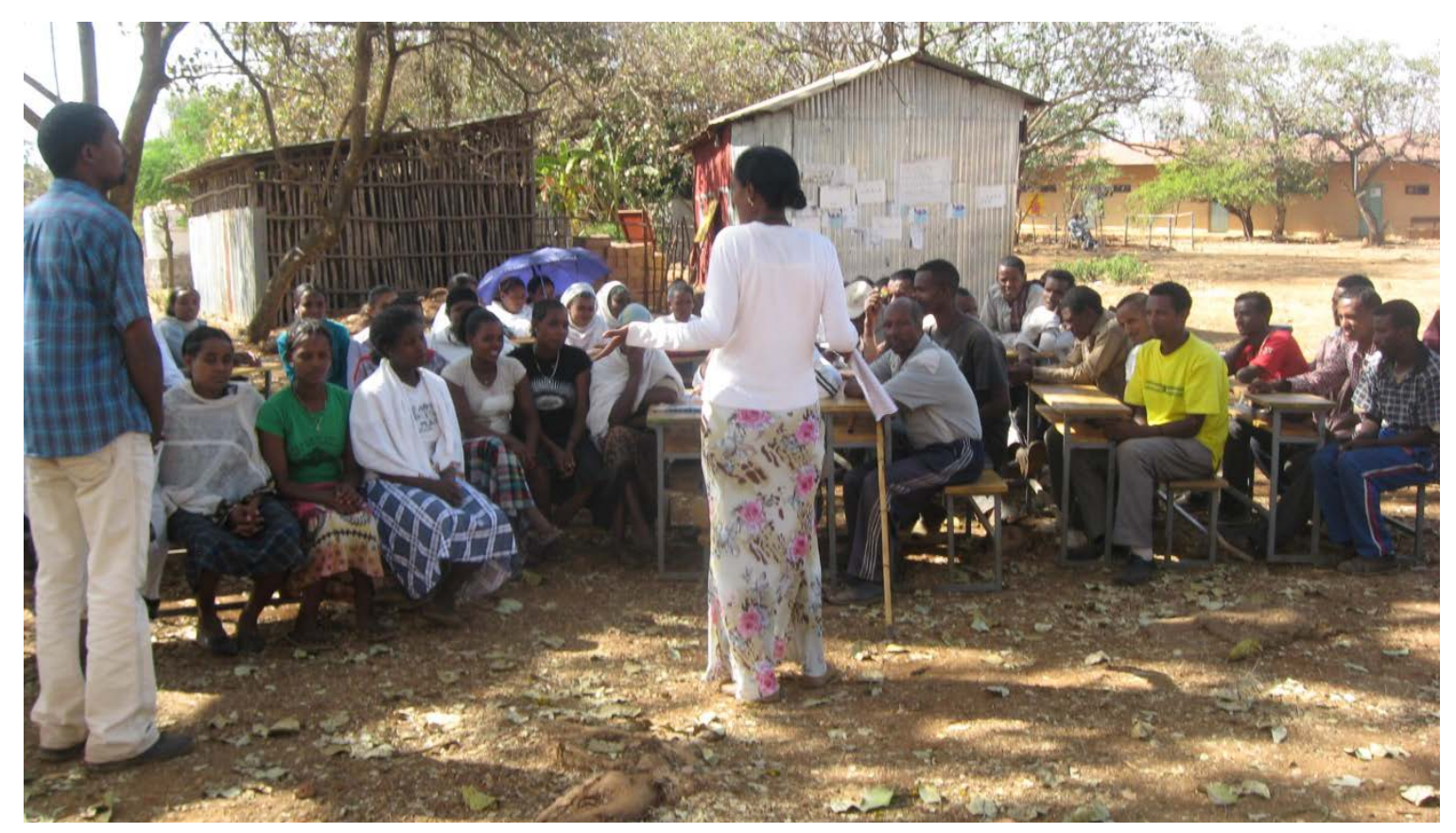




\section{Methods}

Throughout the project, information was collected on the profile of project participants, as well as perceptions of the project by participants and mentors. A baseline survey was undertaken in Bahir Dar (Amhara region) and Mekelle (Tigray region). The survey provided a benchmark of the gender dimensions of marital relationships and HIV transmission within marriage, including communication about HIV and other reproductive health topics, violence in marital relationships, and risk factors within marriage such as infidelity and alcohol use. While it had been anticipated that an endline survey would be undertaken after two years of implementation, this proved not to be feasible due to budgetary constraints.

\section{BASELINE SURVEY}

The baseline survey took place in six districts/woredas, each, of Bahir Dar and Mekelle. ${ }^{7}$ Within study districts/woredas, 72 enumeration areas (EAs) were selected, six EAs per district, in each of the two cities. All selected EAs first underwent a census of all households - or household listing - in order to establish a sampling frame. Once households were listed, a selection of respondents was made using a random number function in SPSS. A sample of 1800 individuals was drawn, consisting of 900 men and 900 women.

The questionnaire used in the study addressed a range of topics, including marital relations, communication and decision-making, health-seeking behavior, HIV/AIDS, stigma and discrimination, voluntary counseling and testing (VCT), PMTCT, domestic violence, fidelity, condom and family planning use, and domestic duties, among others. The questionnaire was pretested and translated into Amharic and Tigrigna.

Eighteen interviewers and three supervisors were recruited in each city and trained for five days on the study instrument. Male interviewers interviewed male respondents, while females interviewers interviewed females. Interviewers were trained to conduct the interview in a private place, away from other household or community members. If the respondent was not home, an appointment was made and interviewers paid up to three visits to the household to locate and interview the respondent.

\section{SERVICE STATISTIC DATA}

Once trained, mentors recruited participants in their local communities by going house-to-house to identify married or cohabiting participants aged 15 to 49 for the 'Kalkidan' groups. Eligible participants were told about the program and invited to join groups at specified locations and times. Participants who wished to take part in the groups were registered, and their demographic details were recorded. Data collected included sex, age, level of education, occupation, parity, and whether

\footnotetext{
7 Mekelle: Kebele 05, 08, 12, Hossana, Endaba Anenyia, Lemlem Deharo; Bahir Dar: Sefene Selam, Gish Abay , Gish Abay , Shume Abo, Hidar 11, Ginbot 20
} 
or not the participant was a migrant or was disabled. In addition, the registration format collected information as to whether the participant's spouse was also taking part in the program.

\section{QUALITATIVE STUDIES OF PERCEPTION OF THE PROGRAM}

Small-scale monitoring studies were undertaken on two occasions during the life of the program. In these studies, selected participants and mentors were asked a list of questions about their participation in the program. Questions included: 'How did you first learn about 'Kalkidan' program?' 'What do people in your community say about the program?' 'Thinking about all the different aspects of the sessions, what do you like the most? What do you like the least?' 'Please give me ideas for how we could improve the program,' among others. Responses were recorded and transcribed verbatim. Results from these interviews were used to improve the program and make it more responsive and relevant to participants' concerns.

This report provides background information on the baseline survey among married couples in lowincome urban areas, as well as participation and perception of participants in the 'Kalkidan' project. 


\section{Results}

\section{BASELINE SURVEY}

At baseline, 1,687 married men and women were interviewed in the two cities, amounting to a 94 percent response rate. On average, married males interviewed were 37 years old, whereas females were an average of 30 years old (Table 1). Females in the sample were more likely to have never attended school (22 percent) compared to males (10 percent), and levels of education were lower in Bahir Dar than in Mekelle. Likewise, less than half of the participating females (46 percent) had ever worked for pay compared to nearly all male respondents (98 percent). The vast majority of respondents were Orthodox Christian (91 percent).

TABLE 1: Selected characteristics of baseline respondents, by study location and sex of the respondent

\begin{tabular}{|c|c|c|c|c|c|c|}
\hline & \multicolumn{2}{|c|}{ Mekelle } & \multicolumn{2}{|c|}{ Bahir Dar } & \multicolumn{2}{|c|}{ All } \\
\hline & $\begin{array}{c}\text { Men } \\
(\mathrm{N}=424)\end{array}$ & $\begin{array}{c}\text { Women } \\
(\mathrm{N}=432)\end{array}$ & $\begin{array}{c}\text { Men } \\
(\mathrm{N}=403)\end{array}$ & $\begin{array}{c}\begin{array}{c}\text { Women } \\
(\mathrm{N}=428)\end{array}\end{array}$ & $\begin{array}{c}\text { Men } \\
(\mathrm{N}=827)\end{array}$ & $\begin{array}{l}\text { Women } \\
(\mathrm{N}=860)\end{array}$ \\
\hline \multicolumn{7}{|l|}{ Age } \\
\hline $18-24$ & 6.1 & 27.5 & 7.9 & 28.3 & 7.0 & 27.9 \\
\hline $25-34$ & 38.4 & 47.0 & 37.5 & 44.2 & 38.0 & 45.6 \\
\hline $35-44$ & 31.1 & 17.4 & 32.8 & 21.3 & 31.9 & 19.3 \\
\hline$>45$ & 24.4 & 8.1 & 21.8 & 6.2 & 23.1 & 7.2 \\
\hline Mean age & 37.0 & 29.6 & 36.6 & 29.5 & 36.8 & 29.6 \\
\hline \multicolumn{7}{|l|}{ Educational attainment } \\
\hline None & 4.2 & 13.7 & 16.7 & 30.8 & 10.3 & 22.2 \\
\hline $1-4$ years & 6.1 & 8.3 & 11.9 & 9.8 & 9.0 & 9.1 \\
\hline $5-8$ years & 25.5 & 29.2 & 20.9 & 19.9 & 23.2 & 24.5 \\
\hline $9+$ years & 64.2 & 48.8 & 50.5 & 39.5 & 57.5 & 44.2 \\
\hline Mean years of schooling & 10.0 & 8.2 & 8.4 & 6.3 & 9.2 & 7.3 \\
\hline Ever worked for pay & 97.9 & 46.8 & 97.8 & 45.8 & 97.8 & 46.3 \\
\hline \multicolumn{7}{|l|}{ Religion } \\
\hline Orthodox Christian & 92.2 & 92.1 & 91.3 & 89.7 & 91.8 & 90.9 \\
\hline Muslim & 7.8 & 7.2 & 6.2 & 8.9 & 7.0 & 8.0 \\
\hline Other & 0.0 & 0.7 & 2.5 & 1.4 & 1.2 & 1.1 \\
\hline Mean age at first marriage & 26.3 & 18.7 & 24.6 & 18.4 & 25.5 & 18.5 \\
\hline
\end{tabular}

Respondents were read a series of statements to assess the extent to which they have social support within their community. Statements related to issues such as having a person from whom they can borrow money or a place to stay in an emergency. Across all social safety nets included, men were significantly more likely to report sources of support compared to females (Table 2). Among men, 66 percent had a person they could confide in about having HIV and 67 percent had a person to confide in about violence. Only 49 percent of women had a confidante to discuss HIV and 59 percent had someone with whom they could discuss domestic violence. Importantly, while 62 percent of men had 
a place in the community to meet other males, only 2 in 5 (40 percent) of women had such a safe space.

TABLE 2: Self-reported social support and safety nets, by sex of respondent

\begin{tabular}{|c|c|c|}
\hline & $\begin{array}{c}\text { Males } \\
(n=827)\end{array}$ & $\begin{array}{l}\text { Females } \\
(n=860)\end{array}$ \\
\hline Agrees with 'There is someone in your community from whom you can borrow money in an emergency.' & $54.5 * * *$ & 35.5 \\
\hline Agrees with 'There is someone in your community whom you could stay with if you had a problem.' & $57.2 * * *$ & 37.4 \\
\hline Agrees with 'There is someone in your community you could confide in about violence in the home.' & $66.6 * * *$ & 59.1 \\
\hline $\begin{array}{l}\text { Agrees with 'There is someone in your community who you could confide in if you found out you were } \\
\text { HIV+.' }\end{array}$ & $66.5 * * *$ & 49.4 \\
\hline Agrees with 'There is someone in your community who would assist you in case of a medical emergency.' & $61.5 * * *$ & 50.8 \\
\hline $\begin{array}{l}\text { Agrees with 'There is a place in your community other than home where you can meet same sex } \\
\text { friends.' }\end{array}$ & $61.8 * * *$ & 39.8 \\
\hline
\end{tabular}

Respondents were asked if they had ever discussed various topics - including reproductive health topics - with their spouse (Table 3). Reported discussion was considerable on most of the topics mentioned. Over 90 percent of both male and female respondents reported having discussed HIV, and 90 percent reported discussing marital fidelity with their partner. Discussion of birth spacing or family planning was less common than the other $\mathrm{RH}$ topics mentioned (87 percent of males and 72 percent of females). The least discussed topic was the number of children to have, reportedly discussed by only 20 percent of males and 31 percent of females.

TABLE 3: Marital discussion on reproductive health topics, by sex of respondent

\begin{tabular}{|c|c|c|}
\hline & $\begin{array}{c}\text { Males } \\
(n=827)\end{array}$ & $\begin{array}{l}\text { Females } \\
(\mathrm{n}=860)\end{array}$ \\
\hline Has discussed HIV and AIDS with their spouse. & $97.1 * \star$ & 93.5 \\
\hline Has talked to their spouse about being faithful. & $94.1 * *$ & 89.6 \\
\hline $\begin{array}{l}\text { Has discussed sharing domestic responsibilities such as cooking and caring for children with their } \\
\text { spouse. }\end{array}$ & $92.8 * *$ & 88.2 \\
\hline Has discussed maternity services such as prenatal care or the place of delivery with their spouse. & 92.6 & 90.2 \\
\hline Has discussed birth spacing or using family planning methods with their spouse. & $86.8 * * *$ & 72.3 \\
\hline Has discussed the number of children to have with their spouse. & 19.9 & $31.1 * * *$ \\
\hline
\end{tabular}

Respondents were asked questions related to marital relationships, including insulting, controlling and violent behavior (Table 4). There was relatively low reporting of negative behavior between spouses, however, these circumstances are likely to be underreported. Six percent of females and 2 percent of males reported having been hit or beaten by their spouse in the last year. When asked if they had ever hit or beaten their spouse, 13 percent of men and 3 percent of women admitted to having done so.

Six percent of women have suspected their partner of being unfaithful and 5 percent of men admit to infidelity. Characteristics associated with men's infidelity were residence in Mekelle, years of education, regular drinking and having beaten their wife in the last year. Multivariate logistic regression reflect that Mekelle men are 3.5 times more likely to report being unfaithful to their wives than Bahir Dar men (results not shown). At the same time, this result may reflect levels of honesty and candor among survey respondents, possibly related to cultural differences in disclosing such 
information. Men who drink two or more times per week are 2.5 times more likely to have been unfaithful $(\mathrm{OR}=2.53 ; \mathrm{p}<0.05)$, and those who have ever beaten their spouse are 2.7 times more likely to have been unfaithful $(O R=2.74 ; p<0.05)$.

TABLE 4: Controlling behavior, domestic violence, and infidelity, by sex of the respondent

\begin{tabular}{|c|c|c|}
\hline & $\begin{array}{c}\text { Males } \\
(n=827)\end{array}$ & $\begin{array}{l}\text { Females } \\
(n=860)\end{array}$ \\
\hline \multicolumn{3}{|l|}{ Controlling or insulting behavior } \\
\hline In the last year, your spouse had insulted you or made you feel back about yourself. & 7.7 & $12.7 * *$ \\
\hline In the last year, your spouse has belittled you or humiliated you in front of others. & 1.9 & 3.6 \\
\hline In the last year, your spouse has done things to scare or intimidate you. & 3.7 & $6.3^{*}$ \\
\hline In the last year, your spouse has threatened to hurt you for someone you care about. & 1.2 & 2.0 \\
\hline \multicolumn{3}{|l|}{ Domestic violence } \\
\hline In the last year, you have been hit or beaten by your spouse & 1.8 & $5.9 * *$ \\
\hline You have ever hit or beaten your spouse. & $13.1 * * *$ & 2.6 \\
\hline \multicolumn{3}{|l|}{ Infidelity } \\
\hline Ever suspected spouse of being unfaithful (yes) & 2.9 & $5.6 * *$ \\
\hline Ever been unfaithful to your spouse (yes) & $4.5 * *$ & 1.9 \\
\hline
\end{tabular}

Levels of reported stigma against those with HIV were relatively low (Table 5). Males in the sample reported lower levels of stigma against those with HIV compared to females. For example, 93 percent of males disagreed with the statement that 'HIV positive children should not be allowed to school with healthy children,' compared to 87 percent of females, a difference that was statistically significant. The area in which there was less consensus appeared to be whether HIV positive people should be allowed to keep their status confidential; 58 percent of males and 46 percent of females agreed with this statement.

TABLE 5: Stigma and discriminatory attitudes towards those with HIV and AIDS, by sex of the respondent

\begin{tabular}{|c|c|c|}
\hline & $\begin{array}{c}\text { Males } \\
(n=827)\end{array}$ & $\begin{array}{l}\text { Females } \\
(n=860)\end{array}$ \\
\hline $\begin{array}{l}\text { Agrees with 'If a person is HIV+, he should be allowed to keep the information } \\
\text { private.' }\end{array}$ & $58.2 * * *$ & 46.3 \\
\hline $\begin{array}{l}\text { Disagrees with 'A child who is HIV+ should not go to school with healthy } \\
\text { children.' }\end{array}$ & $92.7 * * *$ & 87.2 \\
\hline Agrees with 'You would be willing to share food with a person with AIDS.' & 93.3 & 93.3 \\
\hline Agrees with 'You would be willing to take care of a person with AIDS.' & $96.4 * *$ & 93.0 \\
\hline Agrees with 'An HIV+ teacher should be allowed to continue teaching.' & $93.8 * * *$ & 88.1 \\
\hline
\end{tabular}


Use of family planning methods was extremely high. Ninety percent of men and 88 percent of women reported ever having used an FP method, with 81 percent of men and 77 percent of women reporting current use of FP. However, use of condoms was extremely low; 74 percent of males and 90 percent of females reported that they had never used a condom (Table 6). The main reason for not using a condom was trust in one's partner (63 percent of both men and women), refusal to use condoms (31 percent of women and 26 percent of men) and using other FP methods (31 percent of women and 24 percent of men).

TABLE 6: Non-use of condoms and reasons for non-use, by sex of the respondent

\begin{tabular}{lcc}
\hline & Males $(\mathrm{n}=827)$ & Females $(\mathrm{n}=860)$ \\
\hline Never used condoms & 73.9 & $89.7 * * *$ \\
Reasons for non-use of condoms* & & \\
Trust in one's partner & 63.3 & 62.8 \\
Using other contraceptives & 24.1 & $30.6 * *$ \\
Respondent refused & 25.7 & $30.6 *$ \\
Feels no risk of HIV & 4.3 & $7.8 * *$ \\
Partner refused & 2.5 & 3.9 \\
Against religion & 1.8 & 2.1 \\
Other & 5.2 & 5.4 \\
\hline * Percentages may sum to over 100 as more than one response was allowed & \\
Differences between groups significant at: * $p<0.05$ & $\star * p<0.01 \quad * * *<0.001$ &
\end{tabular}

A considerable proportion of the sample has been tested for HIV. Eighty-two percent of men and 92 percent of women had undergone voluntary counseling and testing (VCT) (Table 7). Among those who had received VCT, 79 percent of men and 68 percent of women were tested as a couple. Among those tested, less than two-thirds disclosed their result to their partner. The most common reason for being tested was 'curiosity,' receiving the test before marriage and before pregnancy. Significantly more men were tested out of curiosity, while women tended to be tested within the context of pregnancy.

TABLE 7: Counselling and testing for HIV, by sex of the respondent

\begin{tabular}{lcc}
\hline & Males $(n=827)$ & Females $(n=860)$ \\
\hline Ever been counseled or received HIV testing & 81.5 & $92.2 * * *$ \\
Last HIV test was with spouse/couples' testing & $78.8 * * *$ & 67.5 \\
Disclosed results to anyone ${ }^{1}$ & $86.4 * * *$ & 76.1 \\
Disclosed results to spouse $^{1}$ & 63.0 & 61.7
\end{tabular}

\section{Main reason for being tested ${ }^{2}$}

Wanted to know status/curiosity

$80.5 * * * \quad 67.0$

Before marriage

29.1

31.4

Before getting pregnant

12.0

$39.1 * * *$

Part of routine prenatal visit

3.4

$11.0 * * *$

Was sick

5.1

7.1

Was advised by friend/relative/provider

5.7

7.5

Other

0.4

0.1

${ }^{1}$ Among those who received results ${ }^{2}$ Percentages my sum to more than 100 since more than one reason is possible Differences between groups significant at: $\star_{p}<0.05 \quad * \star p<0.01 \quad \star \star \star p<0.001$ 
Most respondents were tested for HIV in private clinics (25 percent of men and 23 percent of women), public hospitals ( 23 percent of men and 25 percent of women), or public health centers ( 27 percent of men and 35 percent of women).

\section{SERVICE STATISTICS}

Throughout the project period, 26,587 participants took part in the project across the three sites (Table 8). The participation between males and females was fairly balanced. Relatively fewer participants took part in the Addis Ababa program which was due to delays in the implementation because of the required government agreement. Many of the participants in the project were extremely disadvantaged; 46 percent of males and 28 percent of females were daily laborers and about one in seven participants were involved in petty trade.

TABLE 8: Participation in 'Kalkidan' project, by project site and sex

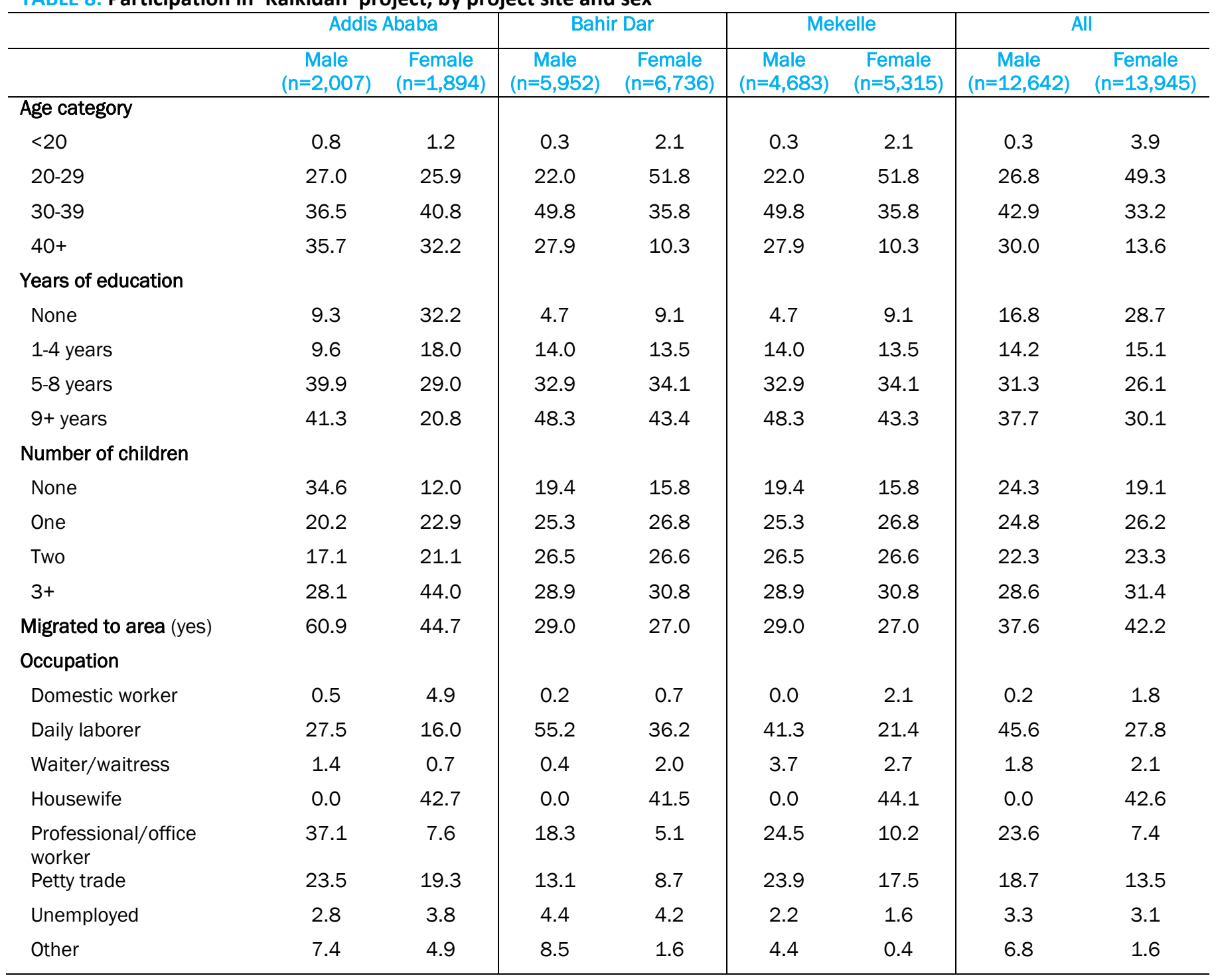




\section{QUALITATIVE STUDY OF THE PROGRAM}

In the last six months of the project, a qualitative study was conducted in Addis Ababa, Bahir Dar and Mekelle. In all, 32 participants who took part in 'Kalkidan' during different phases of the project were interviewed in-depth. Overall, participants viewed the program very positively, with many saying that their marriage and family life had been improved. One of the main areas of family improvement was in the area of communication. Respondents reported increased communication in the family and increased communication on a wider array of topics, as well as spending more time together.

As a result of this program I have started communicating positively with my wife, whether the issues we are discussing is major or minor. -Male, age 38, 12 years education, Bahir Dar

We all used to live separate lives. We talk about things more. I have learnt to talk about things openly. We talk about STI and sanitation and discuss other things. - Male age 68, 14 years education, Addis Ababa

Another notable area of improvement was in men's drinking. Men and women, alike, described men reducing their alcohol consumption and spending more time at home.

My husband used to stay out late. My children would eat dinner and go to sleep early to avoid him. He used to drink a lot. Now he has changed, he comes home early after work and spends time at home. We used to also fight a lot about finances, not anymore. - Female, age 35,12 years education, Addis Ababa

I have learned many things related to family and alcohol use and HIV. How a man treats a women when he is drunk. How a mother and a child suffer from such things. I used to drink before, but now I have reduced my alcohol consumption. I now eat and learn with my family.

- Male, age 43, 8 years education, Addis Ababa

There is a big change in my marriage after Kalkidan. Before, I would eat out in the evenings while my family had nothing to eat. I only cared about myself. I don't do that anymore. Now I share everything I have with my family. -Male, age 43, 8 years of education, Addis Ababa

Respondents frequently described more equitable sharing of household duties, particularly with husbands taking part in maintaining the household.

Yes there are changes because my wife also member of Kalkidan. We have a good home life. When she makes 'enjera,' I prepared the 'wat.' When she makes breakfast, I made the beds and care for the children. - Male, age 27, 9 years education, Mekelle

We live together peacefully and with happiness. I share household tasks like cooking 'wat,' making the beds and taking the kids to school. - Male, age 33, 12 years education, Mekelle

Another topic which was frequently mentioned was PMTCT. Respondents reported a significant increased in knowledge on the topic.

We learnt about PMTCT twice. In the past this issue was always on my mind because I am living with HIV. Now I understand it's possible to have a child safe from HIV. -Female, age 32, 8 years of education, Mekelle

I was so surprised when I learn a positive mother can deliver an HIV-free baby. Now I understand that, a mother live with HIV can live a healthy life and give birth HIV free baby. Female, age 27, 7 years education, Mekelle 
All respondents were very happy with the same-sex sessions. It gave the respondents the chance to share experiences with peers and learn from each other.

It was a good experience having the same sex sessions, and having it separate. It enabled participants to express their feelings and ideas openly. This would not have happened as often if the sessions were held together with the husbands group. -Female, age 25, 12 years education, Bahir Dar

I was able to make some changes in my life like, increasing my self-confidence and overcoming my shyness. -Female, age 27, 7 years of education, Mekelle

Some respondents reported that the mixed sex sessions were not as effective due to shyness, especially among female participants. Others reported that it was a good opportunity for women to voice their views in front of men.

What I liked the most in the mixed session was that it gave an opportunity for the two groups to bring up common issues for the group discussion. Especially for the women, it was a good opportunity to speak their inner feelings in front of their husbands without any fear. -Male, age 42, 10 years of education, Bahir Dar

We get to debate with the men and there are instances where we win and it makes them cringe. They accept their defeat and understand that they are wrong. We both get to understand where we make mistakes. I enjoy it a lot. The men say that women need to bear with their husbands drinking; but we explain to them that this is wrong. - Female, age 35, 12 years education, Addis Ababa

When we mixed with the females once a month, at first we were shy with each other, but then we got comfortable and we learned together openly. The females shone more than us. The mixed sessions enabled my wife and I to openly discuss certain issues. - Male, age 43, 8 years education, Addis Ababa

Respondents made several suggestions concerning how to improve the program. Several respondents would like to see Kalkidan offered to individuals who are not married, such as young adults, commercial sex workers, and daily laborers. Many respondents stated that more couples should get the opportunity to participate in Kalkidan, and that the program should be scaled up to reach more areas.

Because of the things I have learned in Kalkidan, my life has changed and I am so happy. I would like this program should be expanded to reach other areas too. -Male, age 38, 5 years of education, Mekelle 


\section{CONCLUSIONS \& RECOMMENDATIONS}

The 'Kalkidan' project was undertaken in low income areas of three Ethiopian cities. The project aimed to address marital transmission of HIV and AIDs, by improving HIV knowledge, including knowledge of PMTCT, improving gender equity within marital relations, encouraging increased discussion between partners and improving couples' ability to prevent HIV and PMTCT. The project consisted of single-sex groups of married men and women who periodically came together in joint discussions. By the end of the project, over 26,000 married men and women had taken part in the groups, which reflects that feasibility and appropriateness of such a model in urban Ethiopia.

A baseline of nearly 1,700 married men and women was undertaken in two of the project towns, Bahir Dar and Mekelle. Males in the sample reported significantly more social supports and community safety nets than females, spanning issues such as having people in whom they can confide in case of sensitive issues and having people from whom they can borrow money in an emergency. In particular, while 67 percent of men had a confidante in a situation where they found out they were HIV positive, only 49 percent of women had such a person. This may reflect women's greater social isolation and that they have fewer friends than men, or that the stigma related to women having HIV is greater than for men.

Six percent of women reported that their husbands had hit or beaten them in the last year. Thirteen percent of men admitted to having beaten their wives in the past. While 6 percent of women suspected their husbands of infidelity, 5 percent of males admitted to having been unfaithful. In further analysis, men's infidelity was associated with drinking and domestic violence.

Importantly, one of the main changes reported related to participation in the 'Kalkidan' project was changes in men's drinking. Many respondents - both men and women alike - reported that men had reduced or stopped drinking and spent less time outside of the house engaged in these matters. Likewise, participants reported an increase in communication on a range of topics between partners and within the family generally. Men and women both reported that husbands are increasing their involvement in domestic duties and respondents all reported increased knowledge on PMTCT. Many participants suggested that the model be scaled up to a larger segment of the community. 
Heritage Plaza, $4^{\text {th }}$ Floor Addis Ababa ETHIOPIA

popcouncil.org 